\title{
SUV39H1 downregulation induces deheterochromatinization of satellite regions and senescence after exposure to ionizing radiation
}

\author{
Corinne Sidler, Dongping Li, Bo Wang, Igor Kovalchuk* and Olga Kovalchuk*
}

Department of Biological Sciences, University of Lethbridge, Lethbridge, AB, Canada

Edited by:

Alexey Moskalev, Institute of

Biology of Komi Science Center of

Ural Division of RAS, Russia

Reviewed by:

Andrei Seluanov, University of

Rochester, USA

Alexander Y. Maslov, Albert Einstein

College of Medicine of Yeshiva

University, USA

*Correspondence:

Igor Kovalchuk and Olga Kovalchuk 4401 University Drive, Lethbridge,

AB T1K 3M4, Canada

e-mail: igor.kovalchuk@uleth.ca;

olga.kovalchuk@uleth.ca
While the majority of cancer patients are exposed to ionizing radiation during diagnostic and therapeutic procedures, age-dependent differences in radiation sensitivity are not yet well understood. Radiation sensitivity is characterized by the appearance of side effects to radiation therapy, such as secondary malignancies, developmental deficits, and compromised immune function. However, the knowledge of the molecular mechanisms that trigger these side effects is incomplete. Here we used an in vitro system and showed that low-senescent normal human diploid fibroblasts (WI-38) senesce in response to 5 Gy IR, while highly senescent cultures do not show changes in cell cycle regulation and only a slight increase in the percentage of senescent cells. Our study shows that this is associated with changes in the expression of genes responsible for cell cycle progression, apoptosis, DNA repair, and aging, as well as transcriptional and epigenetic regulators. Furthermore, we propose a role of the downregulation of SUV39H1 expression, a histone methyltransferase that specifically trimethylates $\mathrm{H} 3 \mathrm{~K} 9$, and the corresponding reduction in $\mathrm{H} 3 \mathrm{~K} 9 \mathrm{me} 3$ levels in the establishment of IR-induced senescence.

Keywords: senescence, aging, ionizing radiation, epigenetics, SUV39H1, DNA methylation

\section{INTRODUCTION}

Age is a major risk factor for cancer. However, while the majority of cancer patients undergo diagnostic and therapeutic procedures involving ionizing radiation (IR), age-dependent differences in radiation sensitivity have not been well understood. Follow-up studies of patients that have received radiation therapy and studies on survivors of the atomic bombings in Japan have shown the wide variety of side effects associated with those exposures, including the risk of developing secondary cancers (Kleinerman, 2006), compromised immune function (Yamaoka et al., 2004), and developmental deficits (Krasin et al., 2010).

Many of these side effects are probably caused by the exposure of non-tumor tissue to IR, as many of the currently available follow-up studies are based on information on patients that were subjected to less precisely targeted treatment. However, even with current three-dimensional irradiation strategies, residual exposure of healthy tissues to scattered radiation cannot be completely avoided (Joosten et al., 2013). In pediatric patients, the effects of IR on growth and development are a concern (Krasin et al., 2010); in adult patients, the effects of IR on organ function is a greater concern, as the repair capacity in aging organs may be more limited (Krishnamurthy et al., 2006).

Aging is associated with various molecular changes that may affect the outcome of the response to IR. Aging tissues have been shown to accumulate senescent cells (Dimri et al., 1995), which exhibit shortened telomeres (Harley et al., 1990); oxidative damage and oxidative stress (Wolf et al., 2002); decreased fidelity and efficiency of DNA double-strand break repair (Seluanov et al.,
2004); altered chromatin structure (Scaffidi and Misteli, 2006; O'sullivan et al., 2010), including the formation of senescenceassociated heterochromatin foci at the expense of constitutive heterochromatin (Narita et al., 2003); and a pro-inflammatory secretion profile (Rodier et al., 2009).

On the other hand, the response to IR is characterized by the activation of an ataxia telangiectasia mutated (ATM)-dependent DNA damage checkpoint (Bakkenist and Kastan, 2003), which enables DNA repair. Thus, cells recover from the DNA damage checkpoint upon successful DNA repair and removal of the $\gamma$ H2AX DNA damage signal (Keogh et al., 2006). A failure to repair the DNA damage associated with prolonged G2 arrest may result in p53-dependent apoptosis (Lowe et al., 1993), checkpoint recovery followed by mitotic catastrophe (Castedo et al., 2004), or slippage into the G1 phase and undergo senescence (Ye et al., 2013). The extent to which cells become senescent or undergo apoptosis depends on the cumulative dose of IR the cells were exposed to Noda et al. (2012).

Further, the physiology of the response to IR also seems to depend on the state of senescence: senescent cells are more resistant to radiation-induced cell death than their dividing progenitors (Latella et al., 2004). However, the molecular mechanisms underlying the differences between the dividing and senescent cells in response to IR are not yet well understood.

Therefore, in this study we compared the physiological response of WI-38 cells at three different stages of senescence to IR, and evaluated the associated changes in gene expression profiles. Here, we show that the exposure to 5 Gy of IR resulted in 
extensive changes to the gene expression profile. The most prominent physiological response to IR was observed in young cultures, which predominantly underwent senescence. Here we propose a role for SUV39H1 in this establishment of IR-induced senescence.

\section{MATERIALS AND METHODS CELL CULTURE}

WI-38 human fetal lung fibroblasts (ATCC, CCL-75TM, LOT 58110309) were maintained in HyClone minimum essential medium (MEM) Alpha Modification (ThermoScientific) containing $10 \%(\mathrm{v} / \mathrm{v})$ fetal bovine serum (FBS; Gibco) in a humidified Forma Steri-Cycle $\mathrm{CO}_{2}$ Incubator (ThermoScientific) containing $6 \% \mathrm{CO}_{2}$ at $37^{\circ} \mathrm{C}$. WI-38 cells have a replicative limit of $50 \pm 10$ population doublings (PDs). In this study, cultures of three different PDs were used-38 (young), 47 (intermediate), or 54 (old), as previously described (Sidler et al., 2014). The PD number of a culture is the sum of all $\Delta P D=\log _{2}\left(n_{f} / n_{i}\right)$ for each passage, where $n_{f}$ is the final number of cells in a passage and $n_{i}$ is the initial number of cells inoculated.

\section{X-RAY EXPOSURE}

The cells were irradiated with doses of $0,0.5$, and 5 Gy of $90 \mathrm{kVp}$ and $5 \mathrm{~mA}$ at $0.93 \mathrm{~Gy} / \mathrm{min}$ (Faxitron X-ray LLC, Model RX-650). The samples were collected at $48 \mathrm{~h}$ post-exposure unless stated otherwise. Samples for RNA or DNA isolation were snap-frozen in liquid nitrogen and stored at $-80^{\circ} \mathrm{C}$ until further processing. Samples for protein isolation or flow cytometry were processed as described in the subsequent sections.

\section{GENE EXPRESSION PROFILING}

For the determination of gene expression profiles, RNA was extracted from 2 to 3 samples per group using the TRIzol ${ }^{\circledR}$ Reagent (Invitrogen) according to manufacturer's instructions. Total RNA was quantified using NanoDrop2000c (ThermoScientific), and the RNA integrity was determined using a 2100 BioAnalyzer (Agilent). Illumina ${ }^{\circledR}$ HumanHT12-v4 Gene Expression BeadChips were used to determine the transcript levels using 47231 unique probes. Illumina ${ }^{\circledR}$ GenomeStudio software was used for differential expression analysis using an Illumina custom model with an FDR of 0.05. Only genes for which the differential expression analysis was significant at a level of $p<0.05$ and had a $\log 2$ fold change of less than -0.4 or greater than 0.4 were considered for further analysis.

\section{DNA METHYLATION PROFILING}

For DNA methylation profiling, genomic DNA (gDNA) was isolated from cells using the DNeasy ${ }^{\circledR}$ Blood and Tissue Kit (Qiagen). gDNA was recovered in $100 \mu \mathrm{L}$ nuclease-free water. The gDNA was then treated with ribonuclease A $(0.1 \mathrm{mg} / \mathrm{ml}$ final concentration) for $1 \mathrm{~h}$ at $37^{\circ} \mathrm{C}$ and purified by phenol:chloroform extraction. DNA was precipitated by adding $3 \mathrm{M}$ of sodium acetate $(\mathrm{pH} 5.2)$ in the ratio $1: 5$ and $100 \%$ ethanol in the ratio 5:1. DNA pellets were dissolved in $50 \mu \mathrm{L}$ nuclease-free water and quantified using NanoDrop 2000c (ThermoScientific). Illumina ${ }^{\circledR}$ HumanMethylation27 BeadChips were used to determine the methylation levels of more than 28,000 unique CpG sites. Among the BeadChip probes, most of the $\mathrm{CpG}$ sites detected were located in the promoter regions of genes, with a slight overrepresentation of cancer genes. In order to determine the relative methylation levels of specific sites among the different treatment groups, beta values (percentage methylation of a specific CpG site in a specific sample) were determined using Illumina ${ }^{\circledR}$ GenomeStudio software. Differential DNA methylation analyses were performed using an Illumina custom model, which produced diff scores as a measure of significance. Diff scores of $-13 / 13$ were set as cutoff values for significance.

\section{FUNCTIONAL CLASSIFICATION OF GENES}

Online software and databases were used for the functional classification of differentially expressed genes or differentially methylated CpG sites: FunNet Transcriptional Networks Analysis (www.funnet.info), DAVID Bioninformatics Resources 6.7 (Huang da et al., 2009b,a), and the Genecards database (http:// www.genecards.org) (Safran et al., 2010).

\section{QUANTITATIVE REAL-TIME PCR (qRT-PCR)}

Transcription levels of the selected genes were confirmed using qRT-PCR. The RNA samples were treated with DNAse I using an Illustra RNAspin Mini Prep (GE Healthcare) to remove any gDNA contamination. The RNA was quantified by NanoDrop2000c, and 500 ng of RNA was used for cDNA synthesis using the iScript ${ }^{\mathrm{TM}}$ Select cDNA synthesis kit (BioRad). qRT-PCR reactions were set up using the SsoFast ${ }^{\mathrm{TM}}$ EvaGreen ${ }^{\circledR}$ Supermix (BioRad) together with primers specific for the target sequences of interest (S1) and analyzed on a $\mathrm{C} 1000^{\mathrm{TM}}$ Thermo Cycler equipped with a CFX96 ${ }^{\mathrm{TM}}$ Real-Time System (BioRad). PCR conditions were chosen according to the SSoFast guidelines with the annealing temperatures specified for primer pairs (S2).

Each experiment included three biological replicates and two technical replicates per treatment. The HPRT1, RPL13A, and $Y W H A Z$ housekeeping genes were used for the normalization and calculation of transcript levels using qbase ${ }^{\text {PLUS }}$ (Vandesompele et al., 2002).

\section{WESTERN BLOTTING}

Total protein extracts were prepared by sonicating cells harvested from two $10-\mathrm{cm}$ cell culture dishes per sample in $100 \mu \mathrm{L}$ of cold $1 \%$ sodium dodecyl sulfate (SDS) containing protease inhibitor (Roche). The protein amounts were quantified using Bradford assays (BioRad) and measuring the absorbance at $595 \mathrm{~nm}$ using NanoDrop 2000c (ThermoScientific). Equal amounts of proteins per lane $(10-40 \mu \mathrm{g}$ depending on the protein of interest) were separated by SDS-polyacrylamide gel electrophoresis (PAGE) in slab gels of $6-15 \%$ polyacrylamide and transferred to polyvinylidene difluoride (PVDF) membranes (Hybond-P, Amersham Biosciences). The proteins were then incubated with primary antibody overnight at $4^{\circ} \mathrm{C}(\mathrm{S} 2)$, followed by incubation with a secondary horseradish peroxidaseconjugated antibody (S2). Antibody binding was detected using an enhanced chemiluminescence plus immunoblotting detection system (Amersham Biosciences). Chemiluminescence was detected using a FluorChem HD2 camera with FluorChem software (Cell Biosciences). Unaltered PVDF membranes were stained with Coomassie blue (BioRad) to confirm equal protein 
loading. Chemiluminescence signals were quantified using NIH ImageJ 64 software. Pixel intensities of the protein bands of interest were normalized to GAPDH pixel intensities.

\section{FLOW CYTOMETRY ANALYSIS Cell isolation}

Cells from two $10-\mathrm{cm}$ cell culture plates per sample were combined for each treatment. The cells were harvested by trypsinization, centrifugation at $200 \mathrm{~g}$ for $5 \mathrm{~min}$ at $4^{\circ} \mathrm{C}$ and resuspended in $1 \mathrm{~mL}$ Dulbecco's phosphate buffered saline (DPBS) (Lonza) before starting specific staining procedures, except in the case of senescence-associated $\beta$-galactosidase assay, for which the staining was performed in the cell culture plates.

\section{Senescence-associated $\beta$-galactosidase (SA- $\beta$-GAL) assay}

In order to quantify the amounts of senescent cells in response to different X-ray treatments, a flow cytometry-based fluorescent SA- $\beta$-GAL staining was employed. The staining was carried out using the method described by Debacq-Chainiaux et al. (2009) for $1.5 \mathrm{~h}$ at standard culture conditions (Debacq-Chainiaux et al., 2009). Three samples were analyzed for each treatment on a BD FACS Canto II cytometer (BD Biosciences). Measurements included 10,000 events per sample.

\section{Detection of apoptotic, necrotic, and dead cells}

A fluorescein isothiocyanate (FITC) annexin V Apoptosis Detection Kit (BD Pharmigen ${ }^{\mathrm{TM}}$ ) was used to detect the apoptotic, necrotic, and dead cells in the different treatment groups, according to the manufacturer's instructions. Three samples were analyzed per treatment using a BD FACS Canto II cytometer (BD Biosciences). Measurements included 10,000 events per sample.

\section{Detection of proliferating cells}

BrdU is a nucleotide analog that is incorporated into newly synthesized DNA; it is therefore commonly utilized in the detection of DNA synthesis. BrdU staining was performed using a BrdU flow kit (BD Pharmigen ${ }^{\mathrm{TM}}$ ). Cells were pulsed with $1 \mathrm{mM}$ BrdU in MEM for $40 \mathrm{~min}$ at standard culture conditions, and then processed according to the manufacturer's manual. Three samples per treatment were analyzed on a BD FACS Canto II cytometer (BD Biosciences) and 10,000 events were detected per sample.

\section{SUV39H1 OVEREXPRESSION}

The overexpression of SUV39H1 was achieved by transfecting cells with the $p C M V 6-S U V 39 H 1$ expression construct (Origene) using Lipofectamine $\mathrm{T}^{\mathrm{TM}} 2000$ (Invitrogen).

\section{CHROMATIN IMMUNOPRECIPITATION}

For testing of p53 binding to the SUV39H1 promoter, we performed chromatin immunoprecipitation as described previously (Nelson et al., 2006). Briefly, chromatin was cross-linked by treating cells with $1 \%$ formaldehyde for $15 \mathrm{~min}$ and quenching with $125 \mathrm{mM}$ glycine for $5 \mathrm{~min}$. Then, 12-14 million cells were sonicated in $500 \mu \mathrm{L}$ immunoprecipitation buffer $(150 \mathrm{mM} \mathrm{NaCl}$, $50 \mathrm{mM}$ Tris- $\mathrm{HCl}$ [pH 7.5], 5 mM EDTA, 0.5\% NP-40, 1\% Triton $\mathrm{X}-100,0.5 \mathrm{mM}$ phenylmethylsulfonyl fluoride (PMSF), leupeptin, and proteinase inhibitor [Roche]) to shear the DNA into 1001000-bp fragments. Immunoprecipitation was performed using antibodies against rabbit or mouse IgG as a negative control, or rabbit anti-Acetyl-K382 p53 (Cell Signaling), or mouse anti-p53 (Santa Cruz). The DNA fragments were then isolated using $10 \%$ Chele ${ }^{\circledR} 100$ and purified using a QIAquick ${ }^{\circledR}$ PCR purification kit.

ChIP-qRT-PCR was performed like qRT-PCR using the primers listed in S3. Figure 1 shows a representation of the location of the amplicons within the SUV39H1 promoter. The results were calculated by averaging the $2^{(-\mathrm{Ct})}$ values of three samples per treatment and normalizing to $10 \%$ of the values obtained from the input DNA.

\section{STATISTICAL ANALYSIS}

Each data point is an average of three biological replicates \pm standard deviation $(S D)$ unless stated otherwise. Statistical significance was determined by a Student's $t$-test based on a $p$-value of less than 0.05 . Statistical analysis of the gene expression and DNA methylation BeadChips is described in the according methods sections.

\section{RESULTS \\ EXPOSURE TO IR INDUCES DIFFERENTIAL GENE EXPRESSION AT ALL STAGES OF SENESCENCE}

In order to better understand how cell cultures of different stages of senescence react to X-ray irradiation, we exposed cultures at three different stages of senescence to 0.5 or $5 \mathrm{~Gy}$ irradiation and profiled the mRNA expression patterns using Illumina ${ }^{\circledR}$ Gene Expression BeadChips. The results revealed that exposure to $5 \mathrm{~Gy}$ of $\mathrm{X}$-ray affected gene expression profiles more strongly than exposure to $0.5 \mathrm{~Gy}$ (Figure 2A). Cultures with an intermediate senescence ratio (PD 47) showed the highest number of differentially expressed genes (77), followed by cultures with high senescence ratio (PD 54) with 59 differentially expressed genes and cultures with low senescence ratio (PD 38) with 26 differentially expressed genes (S4). Of all these expression changes, there was a bias toward transcription repression (Figure 2B). However, with increasing senescence ratio of the cultures, the number of genes upregulated in response to $5 \mathrm{~Gy}$ increased.

Functional classification was performed to understand the functional implications of the observed changes in expression. The genes related to epigenetic regulation, DNA repair, cell cycle regulation, aging, regulation of transcription, and cell adhesion were among the genes downregulated in response to $5 \mathrm{~Gy}$ in cells of all ages (Figure 2C). The functions that were commonly induced in response to $5 \mathrm{~Gy}$ included cell adhesion, metabolism, and cell signaling and in the older cultures (PD 47 and PD 54), DNA repair, apoptosis, and cell cycle regulation were also induced by irradiation (Figure 2C).

FIGURE 1 | ChIP-qPCR primers targeted to the SUV39H1 promoter. TSS
indicates the transcription start site. Numbers indicate the primer start site
upstream of the TSS.


A

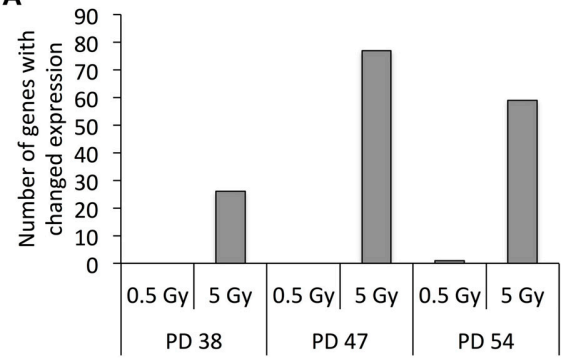

C
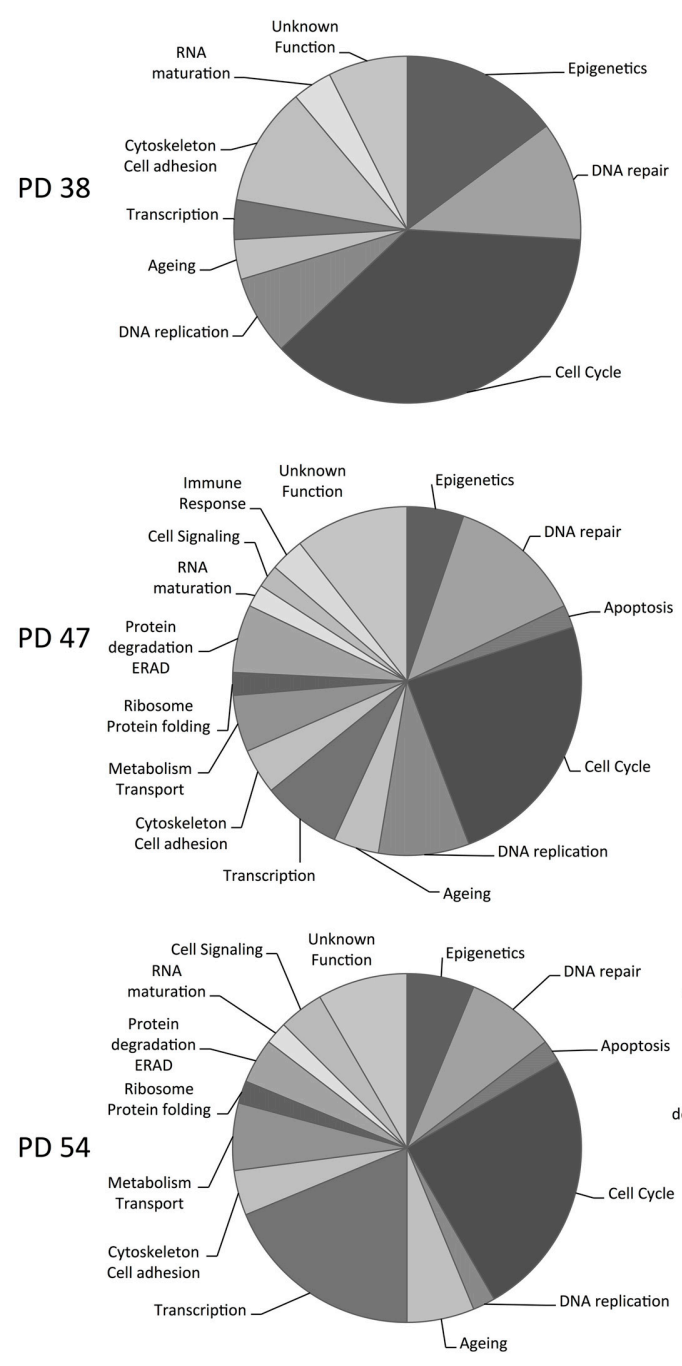

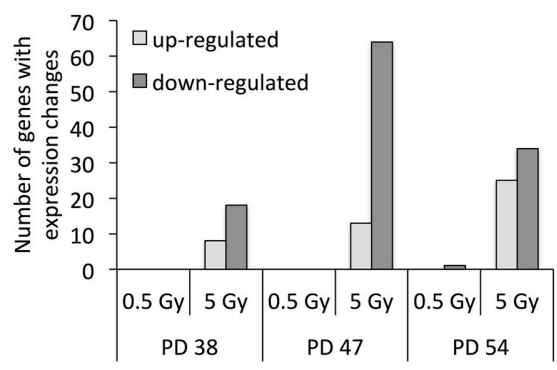

up-regulated
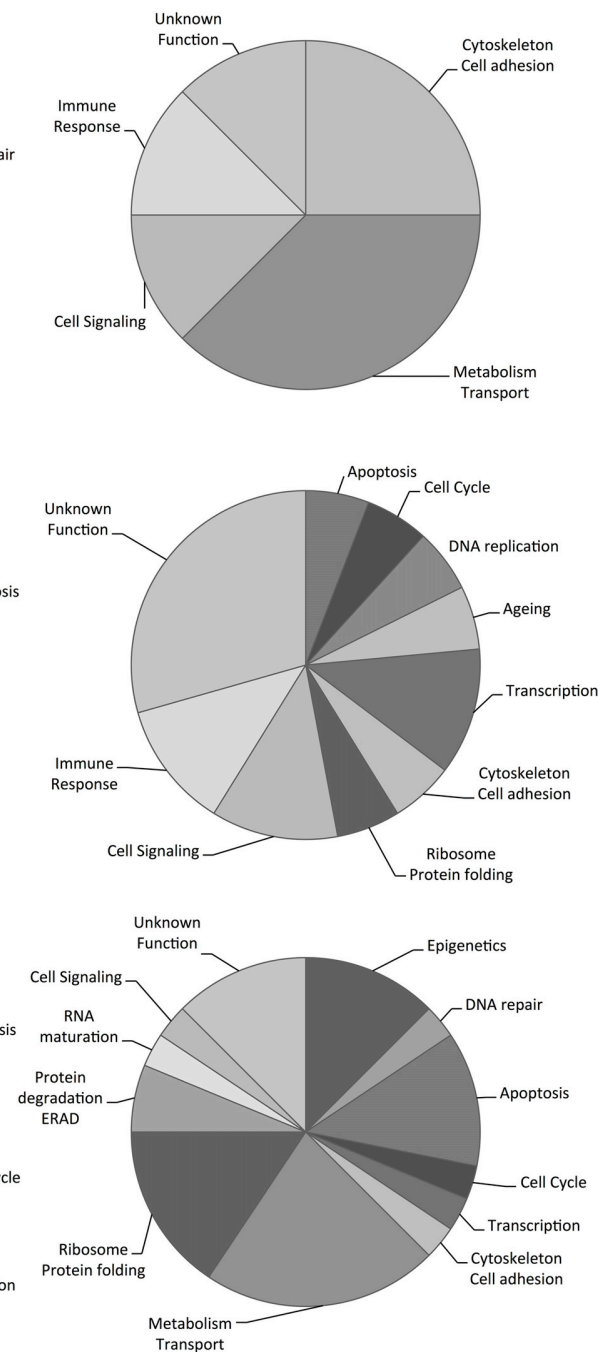

FIGURE 2 | Functional classification of gene expression results. (A) Total number of genes affected by expression changes in response to ionizing radiation. (B) Numbers of up- (light gray) and downregulated (dark gray) genes in response to IR. (C) Functional classification of genes that were differentially expressed in response to $5 \mathrm{~Gy}$ of $\mathrm{IR}$.
PRE-SENESCENT CULTURES INDUCE G2/M ARREST AND SENESCENCE IN RESPONSE TO X-RAY IRRADIATION

IR is known to induce cell cycle arrest at the G1/S or G2/M checkpoints (Terasima and Tolmach, 1963), senescence (Ye et al.,
2013), and apoptosis (Neal and Potten, 1981; Warters, 1992). Correspondingly, we observed downregulation of cell cycle regulators in cultures of all ages and up-regulation of apoptotic genes in intermediate (PD 47), and old (PD 54) cultures. Based on these 
differences in gene expression, we hypothesized that the physiology of the response to X-ray may differ at different stages of senescence.

To test this, we detected proliferating, senescent, and apoptotic cells in cultures exposed to $0.5 \mathrm{~Gy}$ or $5 \mathrm{~Gy}$ by using BrdU, SA- $\beta-G A L$, and annexin V/PI staining respectively. Exposure to 5 Gy resulted in an increase in apoptotic (positive for annexin $\mathrm{V}$, but not PI) and dead (positive for PI staining) cells in cultures of all ages at $48 \mathrm{~h}$ post-exposure, although the differences were significant only for dead cells in the PD 38 and PD 54 cultures (Figure 3A, S5). Further, the number of apoptotic cells in 0.5 Gy-irradiated PD 38 cultures was significantly lower than in non-irradiated cells, while the number of dead cells was not significantly different between the two treatments.

Further, the number of senescent cells at $48 \mathrm{~h}$ after irradiation exposure increased in all cultures exposed to $5 \mathrm{~Gy}$ and in PD 38 cultures exposed to $0.5 \mathrm{~Gy}$ (Figure 3B, S5). The highest increase in senescence ratio was observed in PD 38 cells exposed to $5 \mathrm{~Gy}$.

The analysis of cell cycle distribution based on the BrdU pulse and DNA staining at $48 \mathrm{~h}$ after exposure revealed a significant decrease in S-phase cells in the PD 38 and PD 47 groups with increasing dose of IR (Figure 3C, S5). This is in line with the increased induction of senescence in response to $5 \mathrm{~Gy}$ in PD 38 and PD 47 cells. In addition, this may also indicate that exposure
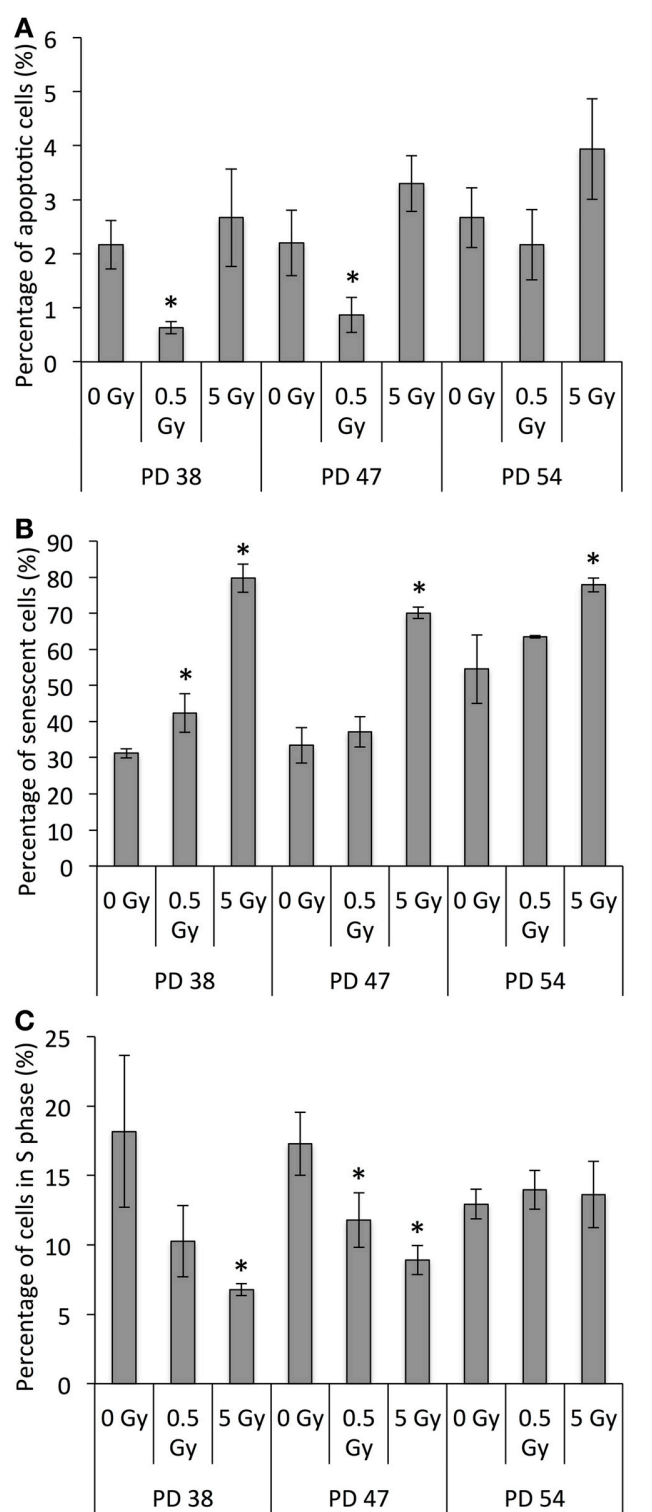

FIGURE 3 | Radiation-induced cell growth arrest, senescence, and cell death. (A) Percentage of apoptotic (Annexin $\vee$ positive) or dead (PI positive) cells as determined by annexin V/PI staining. (B) Percentage of senescent cells as determined by SA- $\beta-G A L$ staining.
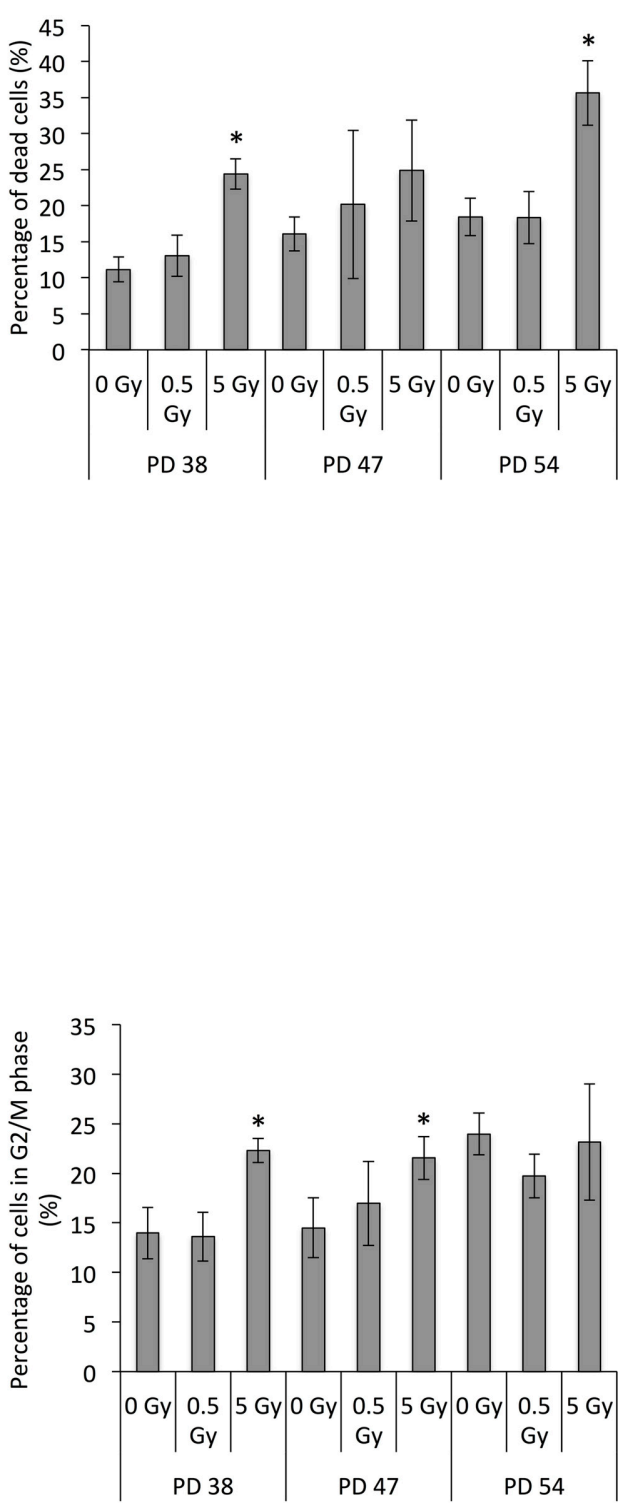

(C) Percentage of cells in the $\mathrm{S}$ or $\mathrm{G} 2 / \mathrm{M}$ phase determined by BrdU incorporation and DNA staining. Averages of three samples $\pm S D$. Asterisks on bars indicate significant difference to the control of the PD level in all graphs. 
to 0.5 and 5 Gy can induce cell cycle arrest. Accordingly, exposure to $5 \mathrm{~Gy}$ resulted in an increased cell population in the $\mathrm{G} 2 / \mathrm{M}$ phase of the cell cycle in PD 38 and PD 47 cells. However, no radiationdependent changes in cell cycle distribution could be detected in PD 54 cultures (Figure 3C, S5).

In summary, the surviving fraction of cells in the young group either enters cell cycle arrest or senescence and the surviving fraction in the more senescent groups is smaller than that in younger cultures and they exhibit senescence rather than cell cycle arrest.

\section{CHANGES IN CELL CYCLE REGULATION AND AGE-RELATED GENE EXPRESSION CORRELATE WITH RADIATION-INDUCED SENESCENCE}

The increase in senescent cells in the irradiated cell cultures of all PD levels correlated with the changes in age-related gene expression. A comparison of the obtained gene expression profiles with microarray signatures from the Human Ageing Genomic Resources (de Magalhaes et al., 2009) and information from Genecards (Safran et al., 2010) showed that five senescenceassociated genes were differentially expressed in one or more experimental groups (Table $\mathbf{1}$ ).

The expression levels of a senescence-associated gene (COL3A1) and a cell cycle regulator (UBE2C) were confirmed by qRT-PCR (S6).

\section{REDUCED SUV39H1 EXPRESSION IN IRRADIATED CULTURES CORRELATES WITH REDUCED H3K9 TRIMETHYLATION}

While none of the differentially expressed transcription factors showed an enrichment of its target genes among the differentially expressed genes, changes in epigenetic regulation may underlie some of the observed changes in gene expression patterns. As both $S U V 39 H 1$, a histone methyltransferase that specifically trimethylates $\mathrm{H} 3 \mathrm{~K} 9$, and $C B X 5$, which binds to trimethylated $\mathrm{H} 3 \mathrm{~K} 9$ (H3K9me3) and mediates its repressive function, were consistently downregulated in PD 38 and PD 47 cells exposed to 5 Gy irradiation (S4), we hypothesized that changes in the chromatin structure may be involved in this response.

When measuring the SUV39H1 expression at the mRNA and protein levels by qRT-PCR and Western blot analysis respectively, we detected a significant senescence-dependent decrease at both the mRNA and protein levels (Figures 4A-C). In addition, results of the Western blot analysis revealed that the SUV39H1 levels were significantly decreased in the PD 38 and PD 47 groups following IR exposure (Figures 4B,C). This finding was further correlated with a significant decrease in the H3K9me3 levels in response to senescence and IR exposure in the PD 47 group (Figures 4B,C). Interestingly, similar observations were made for the global histone 3 levels, although this reduction was less severe than the reduction in $\mathrm{H} 3 \mathrm{~K} 9 \mathrm{me} 3$ levels (Figures 4B,C). Taken together, these results may suggest that the downregulation of SUV39H1 in response to IR results in a loss of heterochromatin, which may result in altered gene expression or genomic instability.

As this downregulation of $\mathrm{SUV} 39 \mathrm{H} 1$ and $\mathrm{H} 3 \mathrm{~K} 9 \mathrm{me} 3$ levels with increasing age or stage of senescence has been observed in multiple models (Scaffidi and Misteli, 2006; Sidler et al., 2013), it probably plays an important role in establishing senescence-related changes to the chromatin structure. If this downregulation of SUV39H1 plays a role in the establishment of radiation-induced senescence, it is expected to occur around the time that cells usually recover from the DNA damage checkpoint, which is between 12 and $24 \mathrm{~h}$ after exposure to irradiation (Xu et al., 2002). In order to test this, we examined $S U V 39 H 1$ transcript and protein levels and studied the induction of senescence based on SA- $\beta$-GAL activity in PD 38 cells exposed to $5 \mathrm{~Gy}$ at different time points after exposure to IR (Figure 5). Our results revealed that the SUV39H1 transcript levels were slightly reduced at $6 \mathrm{~h}$ after exposure and were significantly decreased at 24 and $48 \mathrm{~h}$ after exposure to IR (Figure 5A), which corresponded to the reduced protein levels at the same time points (Figure 5B). This was associated with the trend of reduced $\mathrm{H} 3 \mathrm{~K} 9 \mathrm{me} 3$ levels and the induction of senescence, which was significantly increased $24 \mathrm{~h}$ after exposure to 5 Gy (Figures 5B,C).

\section{SUV39H1 DOWNREGULATION CORRELATES WITH EXPRESSION OF SATELLITE TRANSCRIPTS AND DNA DAMAGE CHECKPOINT}

SUV39H1 is important for pericentric heterochromatin formation and silencing of satellite regions (Peters et al., 2001; Lehnertz et al., 2003). Our previous results indicated that the senescence-associated downregulation of SUV39H1 resulted in the loss of $\mathrm{H} 3 \mathrm{~K} 9 \mathrm{me} 3$ in satellite regions and increased the expression of satellite-derived transcripts (Sidler et al., 2014). Thus, we next tested whether the radiation-induced downregulation of SUV39H1 was associated with increased expression of satellite transcripts. Our results showed that the SAT2 and majSAT

Table 1 | Senescence-associated gene expression.

\begin{tabular}{|c|c|c|c|c|c|c|c|}
\hline Gene & Involvement in ageing & \multicolumn{2}{|c|}{ PD 38} & \multicolumn{2}{|c|}{ PD 47} & \multicolumn{2}{|c|}{ PD 54} \\
\hline CTGF & Upregulated with senescence & & & & 0.43 & & \\
\hline MNT & May induce senescence & & & & & & -0.44 \\
\hline SUV39H1 & H3K9 methylation-dependent induction of senescence & & -0.42 & & -0.43 & & \\
\hline
\end{tabular}

Entries for genes that were upregulated/downregulated with age are based on microarray signatures from Human Ageing Genomic Resources (de Magalhaes et al., 2009). Other gene information is based on Genecards (http://www.genecards.org/) (Safran et al., 2010). Numbers indicate log2-fold changes compared to the controls. 

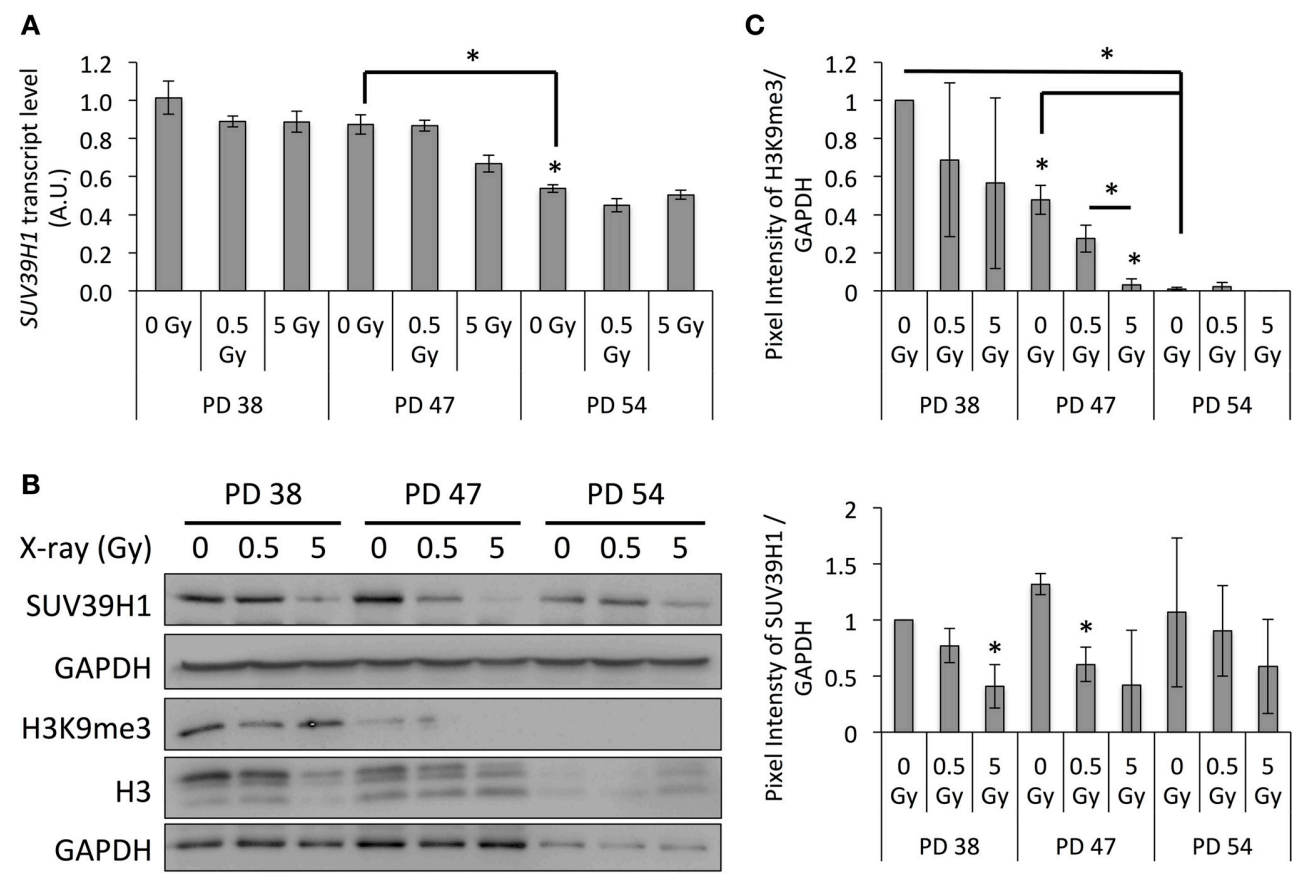

FIGURE 4 | Regulation of SUV39H1 expression and correlation with H3K9me3 levels in response to IR. (A) SUV39H1 transcript levels normalized to PD $380 \mathrm{~Gy}$ (Arbitrary units, A.U.). Averages of three biological repeats with two technical replicas each. Error bars indicate error progression of SDs. (B) Western blots images with respective GAPDH loading controls. (C) Western blot quantifications of the SUV39H1 and H3K9me3 protein levels normalized to pixel intensities in PD $380 \mathrm{~Gy}$. Averages of three biological replicas $\pm S D .{ }^{*} p<0.05$
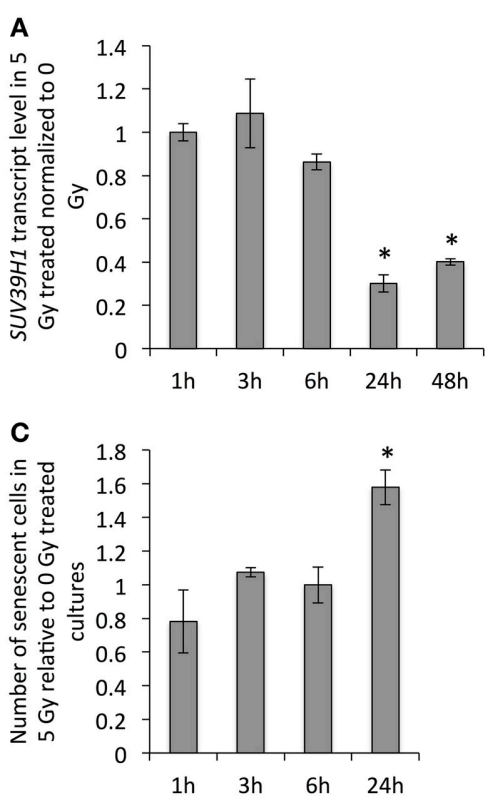

FIGURE 5 | SUV39H1 downregulation occurs during the first $24 \mathrm{~h}$ after exposure. (A) SUV39H1 transcript levels normalized to the expression level $1 \mathrm{~h}$ after exposure. Averages from three biological and two technical replicates per sample. Error bars indicate the error

B
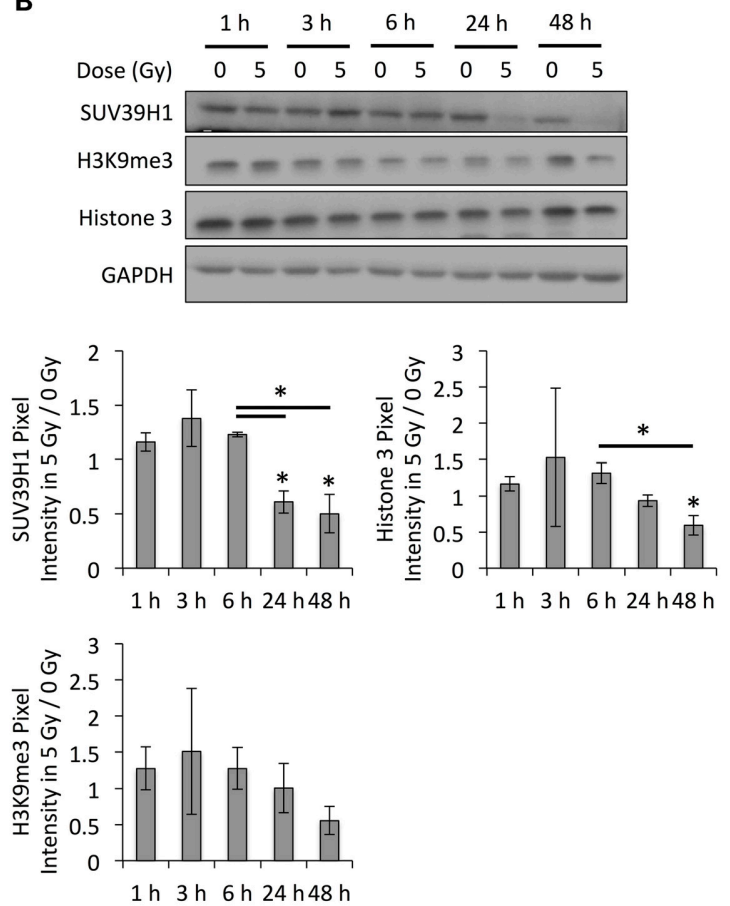

progression of the SDs. Arbitrary units, A.U. (B) Western blot images and quantifications. Averages of three biological replicates $\pm S D$. (C) Fraction of senescent cells as determined by $S A-\beta-G A L$ staining. Averages of three samples $\pm S D$. ${ }^{*} p<0.05$. 
transcripts were induced in IR-exposed PD 38 cells and PD 47 cells, although for PD 47 cells this induction was only significant for majSAT transcripts (Figure 6). Furthermore, both irradiated PD 38 and PD 47 cells exhibited a trend of increased aSAT expression (Figure 6). However, in PD 54 cells, only exposure to 0.5 Gy IR induced an increase in majSAT transcription (Figure 6).

In order to examine whether this increased chromatin relaxation and transcription of satellite regions correlated with genomic instability and DNA damage checkpoint activation, the protein levels of DNA damage checkpoint regulators were detected by Western blotting. Results revealed that exposure to increasing doses of X-ray irradiation resulted in the downregulation of $\mathrm{CHK} 1$ at all $\mathrm{PD}$ levels, while the remaining $\mathrm{CHK} 1$ proteins showed increased phosphorylation levels at Ser345 (Figure 7). The CHK2 protein and phosphorylation levels showed an opposite trend, where IR exposure resulted in a slight increase in the $\mathrm{CHK} 2$ protein levels and a reduction in the phosphorylation levels of Thr68 (Figure 7).

\section{SUV39H1 OVEREXPRESSION INHIBITS RADIATION-INDUCED PREMATURE SENESCENCE}

Our previous study showed that the inhibition of SUV39H1 resulted in the inhibition of cell division and the induction of senescence in pre-senescent cells (Sidler et al., 2014). The observed downregulation of SUV39H1, the reduction in $\mathrm{H} 3 \mathrm{~K} 9 \mathrm{me} 3$ levels and the induction of satellite transcription after exposure to IR, resembled the previously described senescencedependent changes. Thus, as a next step, the role of SUV39H1 in radiation-induced senescence was further examined by overexpressing SUV39H1 in PD 38 cells prior to exposure to $5 \mathrm{~Gy}$ of X-ray. The overexpression of SUV39H1 before IR exposure prevented the IR-dependent induction of senescence (Figure 8).

\section{BINDING OF ACETYLATED p53 TO THE SUV39H1 PROMOTER IS REDUCED AFTER EXPOSURE TO IR}

Since the IR-dependent downregulation of SUV39H1 seemed to play an important role in the induction of senescence, the next step was to examine what might cause this downregulation. p53 was previously shown to indirectly downregulate SUV39H1 expression through the p21-mediated suppression of E2F activity during the DNA damage response following IR, in order to allow for efficient repair of DNA double-strand breaks within heterochromatin regions (Zheng et al., 2014). In addition, MDM2, another p53 target gene, contributed to the decrease in SUV39H1 protein levels through inducing its proteasomal degradation (Mungamuri et al., 2012).

In order to determine whether p53 plays a role in the regulation of SUV39H1 expression to mediate IR-induced senescence, we determined the protein levels of p53 as well as its phosphorylated and acetylated (Luo et al., 2004) active forms by Western blot analysis (Figure 9A). While the p53 protein levels were slightly induced in IR-exposed PD 38 and PD 47 cells, their phosphorylation levels remained almost unaffected (Figure 9A). However, acetylation at K382 of p53 significantly increased in IR-exposed PD 38 cells, and a similar trend was observed in the IR-exposed PD 47 and PD 54 cells (Figure 9A).

Since the acetylated form of $\mathrm{p} 53$ is active in transcriptional regulation (Luo et al., 2004), we were interested in testing whether it may directly regulate SUV39H1 expression. To this end, we scanned the promoter region of SUV39H1 for p53 transcription factor-binding sites (TFBS) using PROMO (Messeguer et al.,
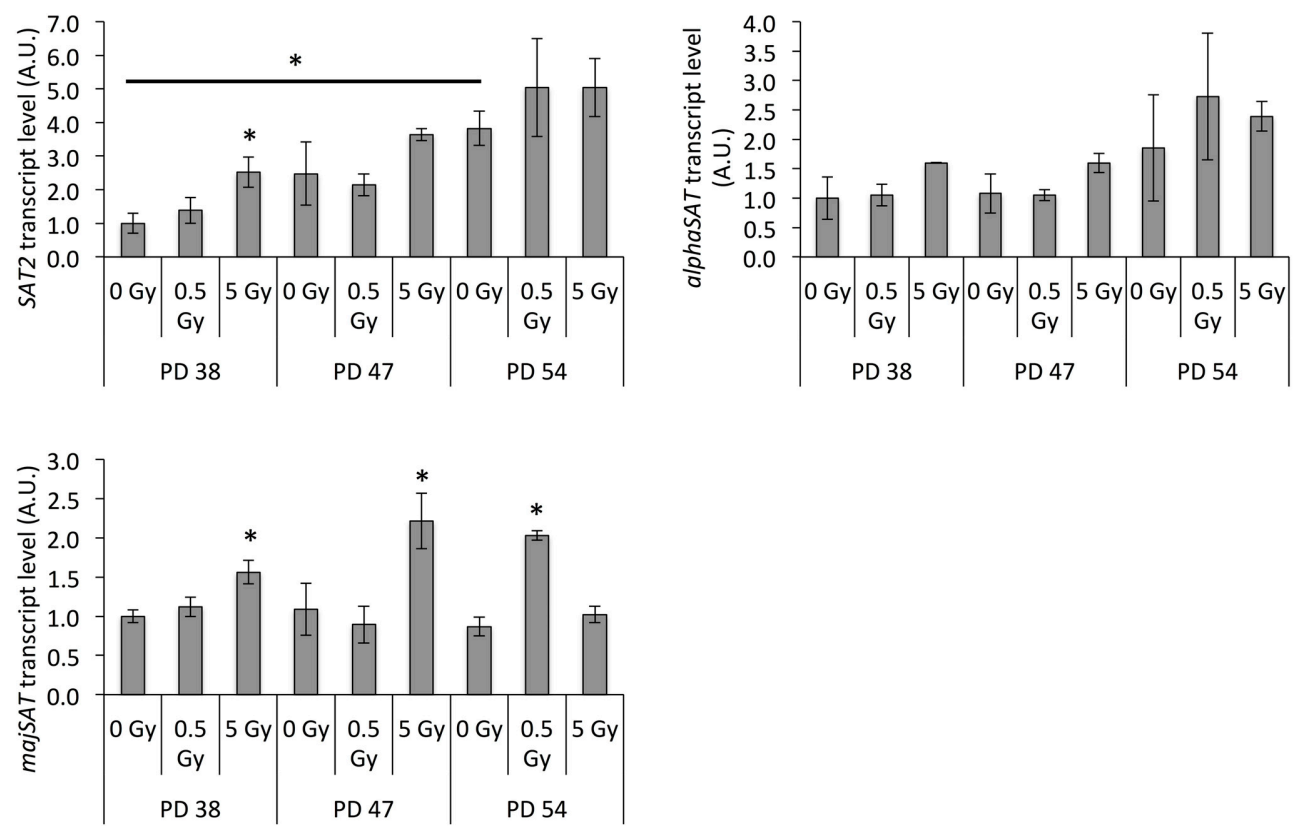

FIGURE 6 | Radiation exposure results in genomic instability. Average transcript levels of satellite transcripts normalized to the expression in PD 380 Gy, shown as arbitrary units (A.U.). Error bars indicate the error progression of $S D$. ${ }^{*} p<0.05$. 

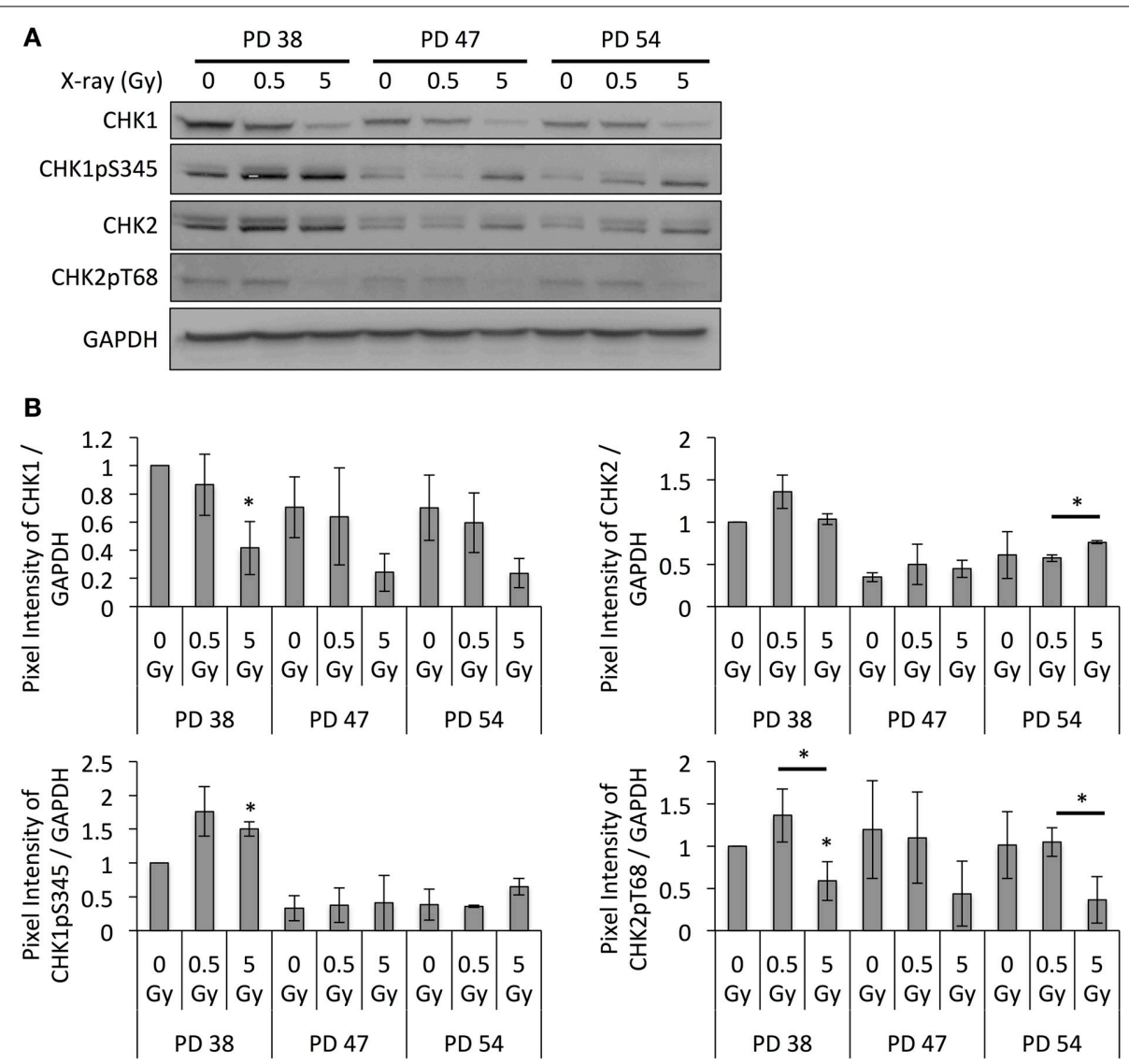

FIGURE 7 | Altered DNA damage checkpoint regulation. (A) Representative Western blot images. (B) Western blot band quantifications of protein levels, normalized to PD 380 Gy. Averages from three biological replicates $\pm S D$. ${ }^{*} p<0.05$.

2002) and TFBIND (Tsunoda and Takagi, 1999) softwares. Results revealed that the promoter region contains several potential TFBS for $\mathrm{p} 53$.

In order to test whether p53 or acetylated p53 directly bind to the SUV39H1 promoter and whether this was affected by exposure to IR, chromatin immunoprecipitation experiments using antibodies targeted to p53 or acetylated p53 were performed after exposure of PD 38 to $5 \mathrm{~Gy}$. Since $p 21$ is a known target for transcriptional regulation by $\mathrm{p} 53$, amplification of the p21 promoter region served as a positive control. Both p53 and acetylated p53 levels increased in the promoter regions of $p 21$ after exposure to 5 Gy (Figure 9B). The p53-dependent increase in the activation of $p 21$ transcription has been associated with the indirect inhibition of SUV39H1 transcription. While the amplification of the SUV39H1 promoter fragments was not significantly different when comparing the IgG negative control and p53 pulldown, it was significantly higher in the acetyl-p53 pulldown samples when compared to IgG controls (Figure 9B). Additionally, the amplification of the SUV1 amplicon was significantly reduced in 5 Gy when compared to the 0 Gy control samples (Figure 9B), suggesting that the binding of active, acetylated p53 to the SUV39H1 promoter is reduced in response to IR.

\section{CHANGES IN THE DNA METHYLATION PATTERNS INVERSELY CORRELATE WITH THE INDUCTION OF SENESCENCE}

Changes in the distribution of repressive histone marks were previously shown to correlate with changes in DNA methylation patterns in the affected genomic regions of senescing human mesenchymal stem cells (Schellenberg et al., 2011). On the other hand, IR is known to affect DNA methylation profiles as well. Several studies have shown that sequence-specific changes in DNA methylation occur after IR and persist through several cell divisions (Kovalchuk et al., 2004; Kaup et al., 2006). Thus, we hypothesized that IR may affect DNA methylation patterns in a senescence-dependent way.

To investigate this hypothesis, we profiled the CpG sites affected by changes in DNA methylation. The results revealed that treatment with $0.5 \mathrm{~Gy}$ induced a higher number of differentially methylated $\mathrm{CpG}$ sites than treatment with $5 \mathrm{~Gy}$ in the PD 38 and PD 47 cultures (Figure 10A, S1). Further, a higher number of CpG sites were affected by differential methylation in the younger cultures (PD 38 and PD 47) exposed to IR than in the older culture (PD 54). Among the observed changes in methylation, hypermethylation was more frequent than hypomethylation (Figure 10B), which is in line with previously reported observations (Kaup et al., 2006). 


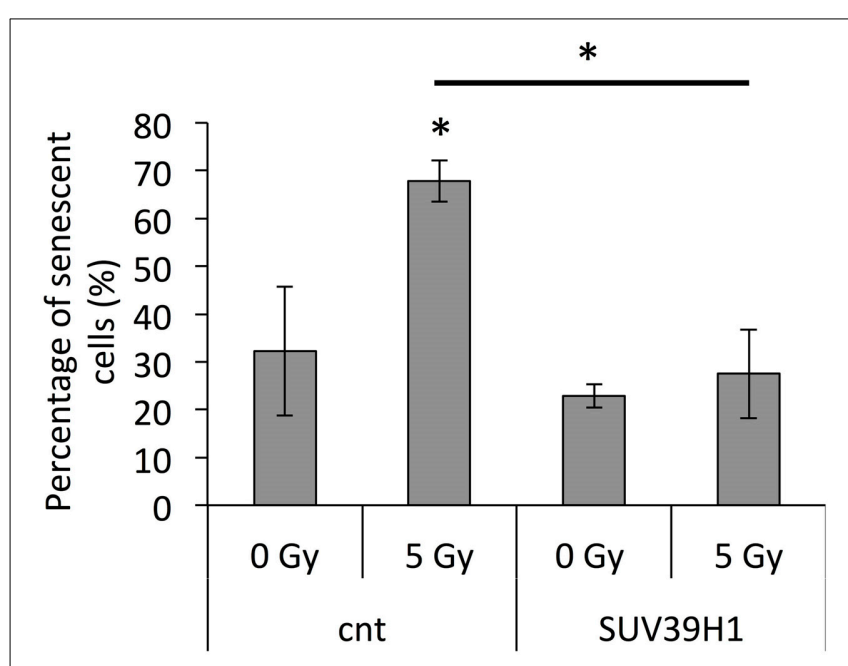

FIGURE 8 | SUV39H1 overexpression inhibits radiation-induced senescence. Averages $\pm S D$ of senescent cells after radiation exposures, when cells had been pre-treated with an SUV39H1 overexpression vector. ${ }^{*} p<0.05$

Interestingly, the clustering analysis revealed that samples clustered primarily based on the stage of senescence of the cultures rather than according to the dose of radiation received (Figure 10C), and only very few CpG sites were differentially methylated in more than one treatment group (Table 2). The changes in the methylation levels of those CpG sites did not correlate with changes in the gene expression of the genes in those regions. Thus, while such changes in methylation may enable cells to adapt to IR, the functional implications of these methylation changes remain to be determined.

\section{DISCUSSION}

Here, we showed that WI-38 cells with low senescence ratio display a distinct physiological response to IR when compared to cells with higher senescence ratio. While cell cycle arrest, apoptosis, and most prominently senescence was induced in response to IR in young cultures, old cultures showed an increase in cell death in response to IR but no significant induction of cell cycle arrest and only a slight increase in the percentage of senescent cells. The induction of senescence before the replicative limit is reached, also termed premature senescence, in response to IR has been previously described (Noda et al., 2012) and both senescence and apoptosis may contribute to several of the observed side effects of radiation therapy in vivo, such as tissue inflammation and fibrosis (Gallet et al., 2011), as well as developmental deficits in pediatric patients (Krasin et al., 2010).

To better understand the molecular changes associated with this increased senescence ratio in irradiated WI-38 cultures, we studied the changes in gene expression profiles, and epigenetic regulation. Cell cycle regulation-related genes comprised the largest fraction of downregulated genes in the 5 Gy-exposed groups at all PD states; this correlates with the observed changes in the cell cycle profiles in PD 38 and PD 47 and the induction of senescence. However, other functional categories, including epigenetic and transcriptional regulators, were also affected by exposure to $5 \mathrm{~Gy}$.

Additionally, senescence has also been associated with changes to chromatin structure and epigenetic regulation. The observation that both SUV39H1, which specifically trimethylates H3K9 (Rea et al., 2000), and CBX5, which binds to H3K9me3 and mediates its repressive function (Bannister et al., 2001; Lachner et al., 2001), are downregulated in IR-treated PD 38 and PD 47 cells suggests that they may play a role in the response to IR. This downregulation of SUV39H1 was confirmed at the RNA and protein levels and corresponded with reduced $\mathrm{H} 3 \mathrm{~K} 9 \mathrm{me} 3$ levels.

In contrast with our observations, however, another study described an increase in the SUV39H1 and H3K9me3 protein levels during senescence or in response to genotoxic or oxidative stress (Bosch-Presegue et al., 2011). However, this may depend on the time points considered: while an increase in the SUV39H1 protein levels during the initial stress response or establishment of senescence may be important to limit genomic instability or adjust gene expression patterns such as by silencing the promoters of E2F target genes (Nielsen et al., 2001; Narita et al., 2003), the downregulation of SUV39H1 may be relevant for the maintenance of cell cycle arrest or senescence in the case of unsuccessful DNA repair.

The disruption of the human SUV39H genes SUV39H1 and $S U V 39 H 2$ has been previously shown to induce a loss of $\mathrm{H} 3 \mathrm{~K} 9 \mathrm{me} 3$ in constitutive heterochromatin regions, including the telomere regions (Garcia-Cao et al., 2004), thereby resulting in deheterochromatinization and genomic instability (Peters et al., 2001). In addition, SUV39H1 has also been shown to act as a co-repressor to several transcription factors by its recruitment to and histone methylation in the promoter regions of specific genes (Nielsen et al., 2001; Jang et al., 2007; Cherrier et al., 2009; Wakabayashi et al., 2011; Mungamuri et al., 2012). Further, SUV39H is also required for chromatin condensation and mitotic progression (Melcher et al., 2000; Park et al., 2011). The observed downregulation of $S U V 39 H 1$ in response to IR may therefore result in G2/M arrest or deheterochromatinization resulting in genomic instability and stress-induced premature senescence.

We observed increased transcriptional abundance from satellite regions that are normally kept silent through SUV39H1dependent $\mathrm{H} 3 \mathrm{~K} 9$ trimethylation, suggesting that the IR-induced downregulation of SUV39H1 induced the heterochromatin relaxation in the pericentric satellite regions. Our previous results showed such an induction of transcriptional activation of the pericentric satellite regions to be associated with the reduction of $\mathrm{H} 3 \mathrm{~K} 9 \mathrm{me} 3$ levels in those regions during replicative senescence (Sidler et al., 2014), suggesting that the heterochromatin relaxation in those regions may contribute to genomic instability and growth arrest.

This transcriptional activation of the satellite regions correlated with the continued activation of $\mathrm{CHK} 1$, while the protein levels of CHK1 were reduced. CHK1 expression has been described to be cell cycle-dependent from the $\mathrm{S}$ to the $\mathrm{M}$ phases of the cell cycle (Kaneko et al., 1999), and CHK1 activation in response to DNA damage is responsible for long-term G2/M cell cycle arrest, as well as for cell cycle re-entry followed by apoptosis or G1 arrest and senescence, depending on the p53 and p21 status 

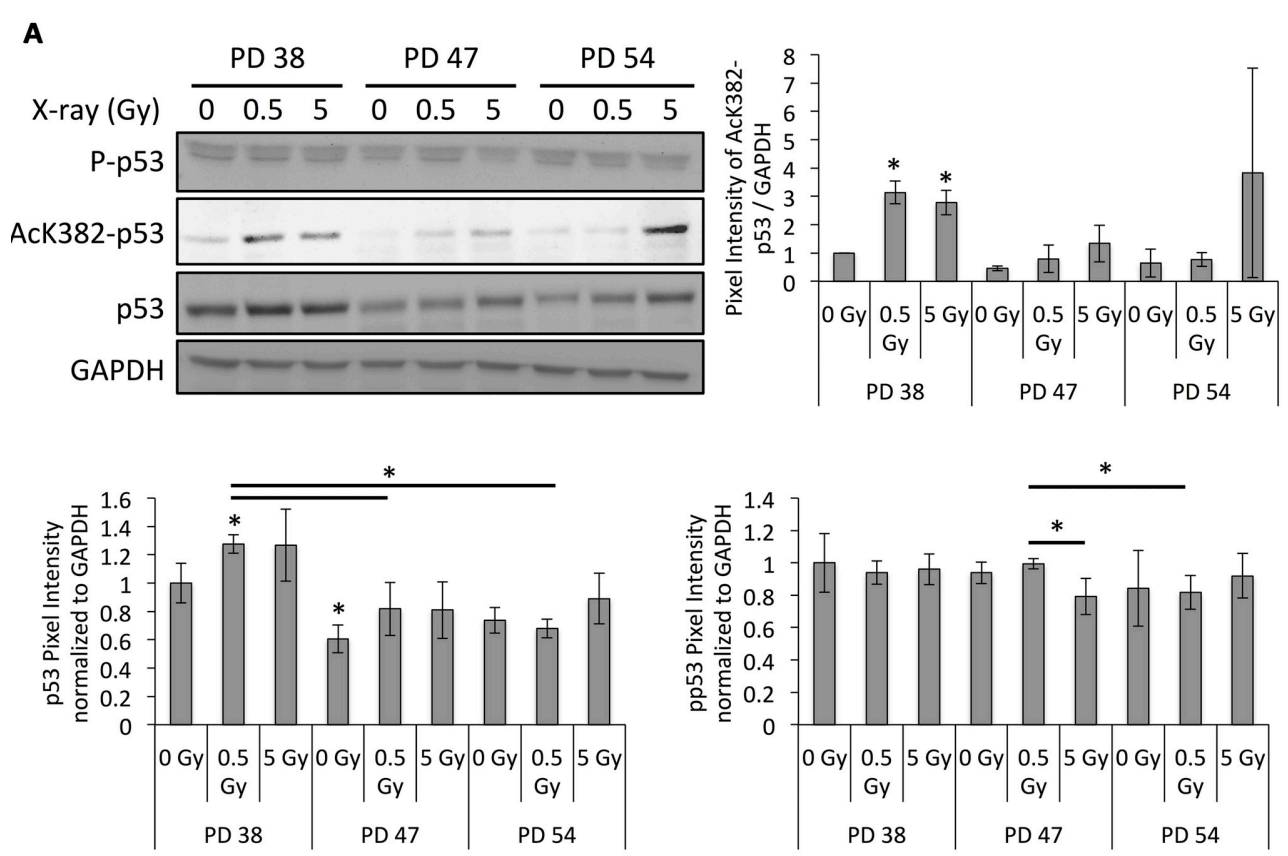

B
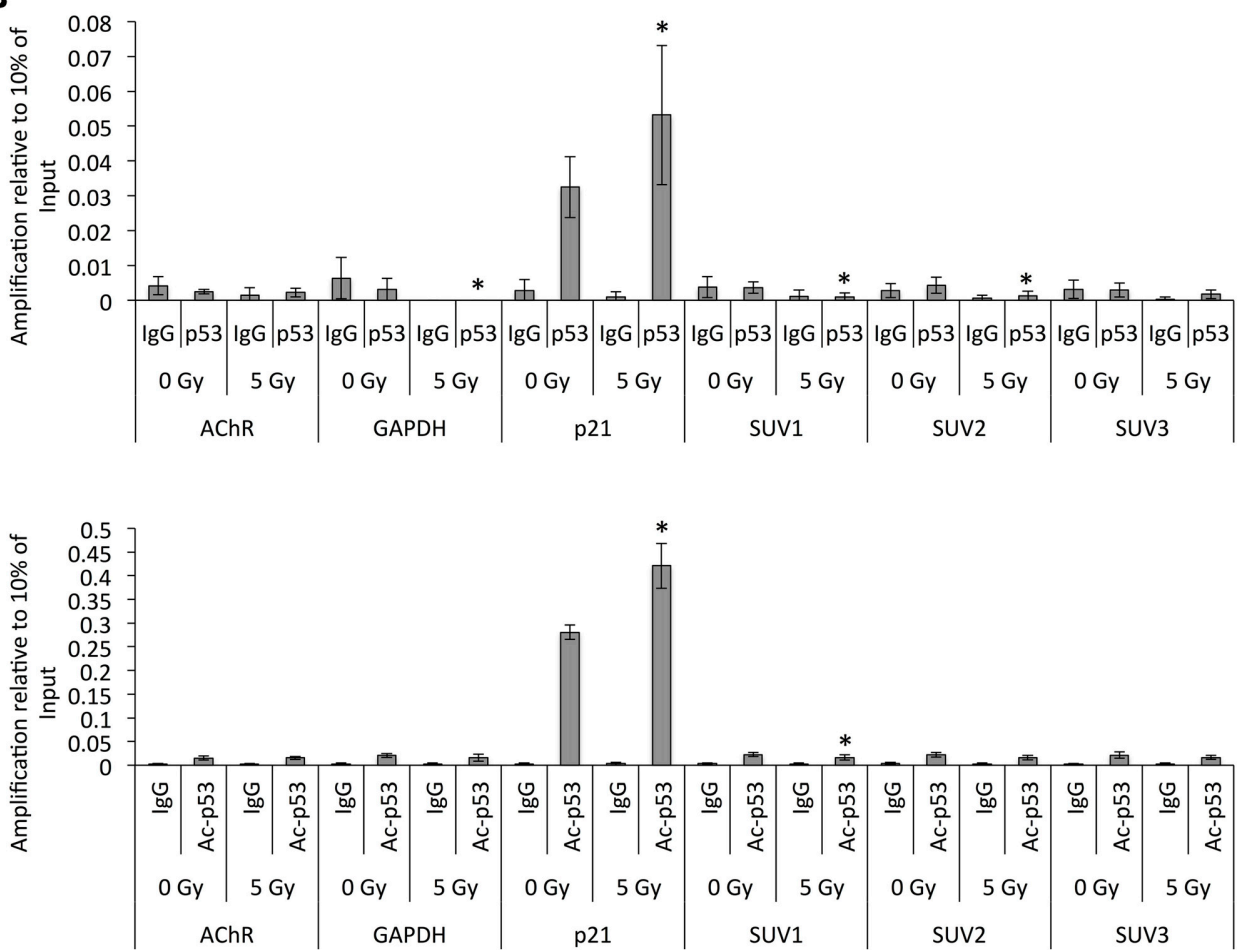

FIGURE 9 | Altered p53 activation and binding to the SUV39H1 promoter after irradiation. (A) Representative Western blots images and quantification of band intensities of the protein levels normalized to PD 38
$0 \mathrm{~Gy}$. Averages from three biological replicates $\pm S D$. (B) ChIP-qRT-PCR target amplification normalized to $10 \%$ of the amplification from input DNA fragments. Averages from three biological replicates $\pm S D$. ${ }^{*} p<0.05$. of the cell (Poehlmann et al., 2011). Thus, the observed continued phosphorylation of $\mathrm{CHK} 1$ may indicate that the cells exposed to X-ray irradiation are in a prolonged $\mathrm{G} 2 / \mathrm{M}$ arrest $48 \mathrm{~h}$ postexposure or have slipped into a G1 arrest. Interestingly, CHK1 has also previously been shown to be downregulated in response to DNA damage or ectopic p53 activation in a p21- and RBdependent manner (Gottifredi et al., 2001). The same regulatory pathway was associated with the downregulation of SUV39H1 
A

C

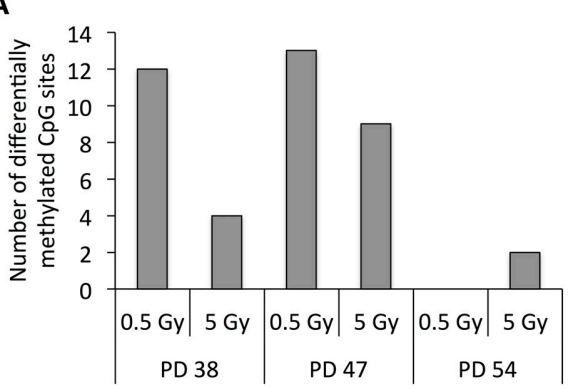

B

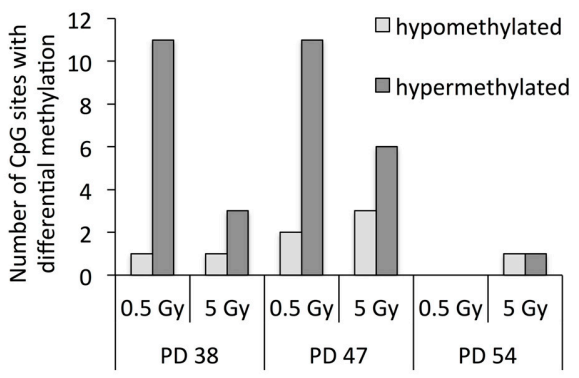

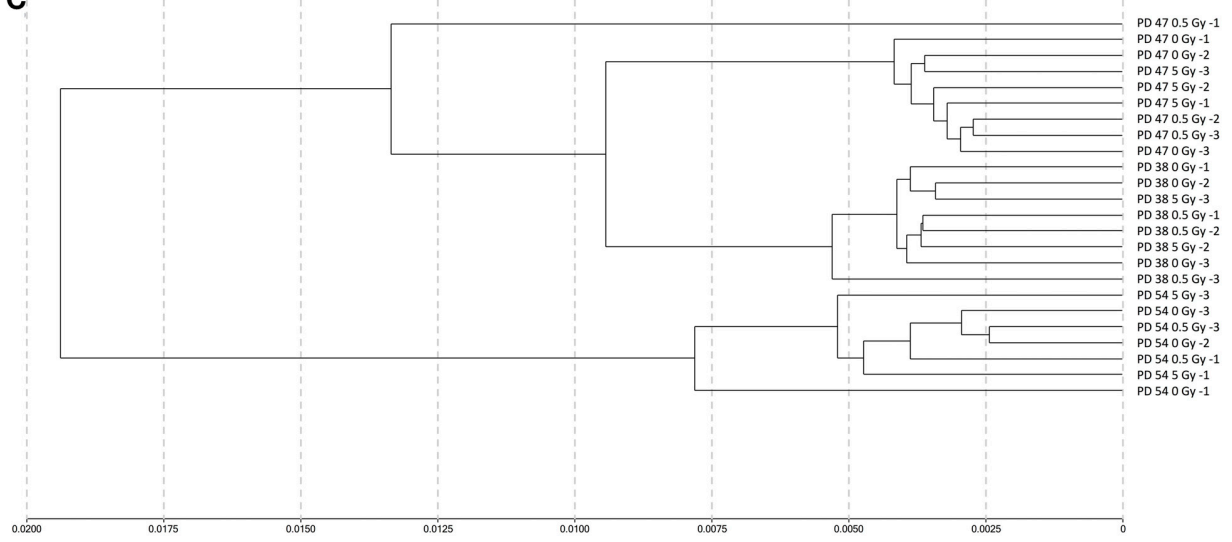

FIGURE 10 | Changes in the DNA methylation pattern in response to senescence and $\mathbf{X}$-ray irradiation. (A) Numbers of $\mathrm{CpG}$ sites affected by differential methylation when comparing cells of different passages exposed to different doses of X-ray irradiation. (B) Numbers of hyper- (dark gray) and hypo- (light gray) methylated CpG sites in irradiated pre-senescent and senescent cultures. (C) Cluster analysis.
Table 2 | CpG sites affected by change in methylation in more than one experimental group.

\begin{tabular}{|c|c|c|c|c|c|c|c|}
\hline & \multirow[b]{2}{*}{$\begin{array}{l}\text { Genes in } \\
\text { this region }\end{array}$} & \multicolumn{2}{|c|}{ PD 38} & \multicolumn{2}{|c|}{ PD 47} & \multicolumn{2}{|c|}{ PD 54} \\
\hline & & $0.5 \mathrm{~Gy}$ & $5 \mathrm{~Gy}$ & $0.5 \mathrm{~Gy}$ & $5 \mathrm{~Gy}$ & $0.5 \mathrm{~Gy}$ & $5 \mathrm{~Gy}$ \\
\hline Chr1:110031996 & GSTM1 & & & - & - & & \\
\hline Chr9:113976778 & SUSD1 & & + & + & & & + \\
\hline Chr16:30841835 & LOC283932 & & & + & + & & \\
\hline Chr17:38531106 & NBR2 & + & & + & & & \\
\hline Chr19:10352577 & TYK2 & & & - & - & & \\
\hline
\end{tabular}

+ indicates hypermethylation, - indicates hypomethylation.

expression in response to DNA damage (Zheng et al., 2014). Thus, CHK1 and SUV39H1 may be co-regulated during the long-term DNA damage response and may mediate the slippage into the G1 phase of the cell cycle followed by senescence.

While previous studies have focussed on the effect of the differential expression of SUV39H1 on the induction of apoptosis (Mungamuri et al., 2012) or DNA repair (Zheng et al., 2014) in response to IR, we demonstrated that this altered expression may also play a role in the induction of senescence. Our previous results showed that $S U V 39 H 1$ overexpression in senescent cells induced cell division, while SUV39H1 inhibition in dividing cells slightly inhibited cell division (Sidler et al., 2014). The overexpression of SUV39H1 prior to exposure to IR compensated for the radiation-induced downregulation of SUV39H1, preventing the induction of senescence.

The downregulation of SUV39H1 in response to IR also seems to be at least in part dependent on p53, since it is correlated with the induction of K382 acetylation of p53 and the reduction of acetylated p53 in the promoter region of SUV39H1. Together with the previous reports that showed the indirect effect of p53-mediated transcriptional regulation on the expression of SUV39H1 (Mungamuri et al., 2012; Zheng et al., 2014), these results may indicate a crucial role for this regulatory pathway in the long-term response to DNA damage.

Additionally, SUV39H1 and trimethylated H3K9 have been shown to recruit DNA methyltransferases at least in some sequence contexts and target them for DNA methylation (Fuks et al., 2003; Lehnertz et al., 2003). Thus, the reduced expression of SUV39H1, which correlates with the reduction in H3K9me3 levels, may also correlate with changes in DNA methylation.

Investigating the DNA methylation levels showed that IR induces changes in DNA methylation in the cells. In this case, younger cultures (PD 38 and PD 47) were more affected and exhibited a higher number of differentially methylated $\mathrm{CpG}$ sites in response to $0.5 \mathrm{~Gy}$ and $5 \mathrm{~Gy}$. Further, site-specific $\mathrm{CpG}$ hypermethylation was observed more frequently than CpG hypomethylation, which is in line with previous observations (Kaup et al., 2006). As the Illumina ${ }^{\circledR}$ HumanMethylation 27 BeadChip primarily contains probes that detect methylated CpGs in the promoter 
regions of genes, it enables the identification of changes in DNA methylation that are mainly considered to play roles in the regulation of gene expression. While the expression of the genes was not affected by the differential methylation in their promoter regions, these changes may have allowed the cells to adapt to the IR. Further, the observation that the DNA methylation profiles are similar between cultures of the same PD level regardless of the dose of radiation received may indicate that either the changes in IR-induced DNA methylation show a high variability between cells or that the potential DNA methylation changes induced by IR do not predominantly affect the CpGs within promoter regions.

On the other hand, the observation that the highest number of changes in DNA methylation was observed in 0.5 Gy-irradiated PD 38 and PD 47 cells, followed by 5 Gy-irradiated PD 38 and PD 47 cells may indicate that changes in CpG methylation following IR exposure may depend on cell division. Accordingly, the numbers of differentially methylated CpG sites detected in the different experimental groups roughly inversely correlated with the extent to which the cultures underwent IR-induced senescence. A recent study showed that human diploid fibroblasts and normal human bronchial epithelial cells that were exposed to ${ }^{137} \mathrm{Cs}$ and did not undergo any further cell division after IR exposure did not show any significant changes in DNA methylation (Lahtz et al., 2012). Thus, senescent cells may be less susceptible to changes in DNA methylation in response to IR when compared to dividing cells.

In summary, we demonstrated that human diploid fibroblasts at three different stages of senescence showed different physiological responses to IR. While cultures with low and intermediate senescence ratios (PD 38 and PD 47) showed induction of G2/M cell cycle arrests, PD 38 and PD 54 cultures contained a higher percentage of dead cells $48 \mathrm{~h}$ after exposure to $5 \mathrm{~Gy}$ IR. More significantly, PD 38 and PD 47 cells exposed to IR underwent senescence. This was associated with changes in the expression of cell cycle regulators and senescence-associated genes, which may be modulated by changed expression or activity of several transcription factors. Further, SUV39H1 as well as CBX5, an HP1 homolog, were found to be downregulated in both PD 38 and PD 47 cells exposed to IR, and were correlated with reduced H3K9me3 levels and induced expression of transcripts from pericentric satellite regions. While such downregulation of SUV39H1 in response to DNA-damaging agents was previously associated with the induction of apoptosis or the facilitation of DNA repair, we suggest that this downregulation may also be associated with the induction of senescence in normal human diploid fibroblasts. This seems to at least in part depend on p53-dependent transcriptional suppression, suggesting that $\mathrm{p} 53$-mediated regulation of SUV39H1 expression plays a role in the long-term DNA damage response. Within an organism, such an induction of senescence in dividing cells exposed to IR may interfere with the normal development and repair of a tissue or organ and thus contribute to side effects associated with IR.

\section{ACKNOWLEDGMENTS}

We thank Rommy Rodriguez-Juarez, Jody Filkowski, and Julian St. Hilaire for their technical support.

\section{SUPPLEMENTARY MATERIAL}

The Supplementary Material for this article can be found online at: http://www.frontiersin.org/journal/10.3389/fgene. 2014.00411/abstract

\section{REFERENCES}

Bakkenist, C. J., and Kastan, M. B. (2003). DNA damage activates ATM through intermolecular autophosphorylation and dimer dissociation. Nature 421, 499-506. doi: 10.1038/nature01368

Bannister, A. J., Zegerman, P., Partridge, J. F., Miska, E. A., Thomas, J. O., Allshire, R. C., et al. (2001). Selective recognition of methylated lysine 9 on histone H3 by the HP1 chromo domain. Nature 410, 120-124. doi: 10.1038/ 35065138

Bosch-Presegue, L., Raurell-Vila, H., Marazuela-Duque, A., Kane-Goldsmith, N., Valle, A., Oliver, J., et al. (2011). Stabilization of Suv39H1 by SirT1 is part of oxidative stress response and ensures genome protection. Mol. Cell 42, 210-223. doi: 10.1016/j.molcel.2011.02.034

Castedo, M., Perfettini, J. L., Roumier, T., Andreau, K., Medema, R., and Kroemer, G. (2004). Cell death by mitotic catastrophe: a molecular definition. Oncogene 23, 2825-2837. doi: 10.1038/sj.onc. 1207528

Cherrier, T., Suzanne, S., Redel, L., Calao, M., Marban, C., Samah, B., et al. (2009) p21(WAF1) gene promoter is epigenetically silenced by CTIP2 and SUV39H1 Oncogene 28, 3380-3389. doi: 10.1038/onc.2009.193

Debacq-Chainiaux, F., Erusalimsky, J. D., Campisi, J., and Toussaint, O. (2009). Protocols to detect senescence-associated beta-galactosidase (SA-betagal) activity, a biomarker of senescent cells in culture and in vivo. Nat. Protoc. 4, 1798-1806. doi: 10.1038/nprot.2009.191

de Magalhaes, J. P., Curado, J., and Church, G. M. (2009). Meta-analysis of age-related gene expression profiles identifies common signatures of aging. Bioinformatics 25, 875-881. doi: 10.1093/bioinformatics/btp073

Dimri, G. P., Lee, X., Basile, G., Acosta, M., Scott, G., Roskelley, C., et al. (1995). A biomarker that identifies senescent human cells in culture and in aging skin in vivo. Proc. Natl. Acad. Sci. U.S.A. 92, 9363-9367. doi: 10.1073/pnas.92. 20.9363

Fuks, F., Hurd, P. J., Deplus, R., and Kouzarides, T. (2003). The DNA methyltransferases associate with HP1 and the SUV39H1 histone methyltransferase. Nucleic Acids Res. 31, 2305-2312. doi: 10.1093/nar/gkg332

Gallet, P., Phulpin, B., Merlin, J. L., Leroux, A., Bravetti, P., Mecellem, H., et al. (2011). Long-term alterations of cytokines and growth factors expression in irradiated tissues and relation with histological severity scoring. PLoS ONE 6:e29399. doi: 10.1371/journal.pone.0029399

Garcia-Cao, M., O’sullivan, R., Peters, A. H., Jenuwein, T., and Blasco, M. A. (2004). Epigenetic regulation of telomere length in mammalian cells by the Suv39h1 and Suv39h2 histone methyltransferases. Nat. Genet. 36, 94-99. doi: 10.1038/ ng1278

Gottifredi, V., Karni-Schmidt, O., Shieh, S. S., and Prives, C. (2001). p53 downregulates CHK1 through $\mathrm{p} 21$ and the retinoblastoma protein. Mol. Cell. Biol. 21, 1066-1076. doi: 10.1128/MCB.21.4.1066-1076.2001

Harley, C. B., Futcher, A. B., and Greider, C. W. (1990). Telomeres shorten during ageing of human fibroblasts. Nature 345, 458-460. doi: 10.1038/345458a0

Huang da, W., Sherman, B. T., and Lempicki, R. A. (2009a). Bioinformatics enrichment tools: paths toward the comprehensive functional analysis of large gene lists. Nucleic Acids Res. 37, 1-13. doi: 10.1093/nar/gkn923

Huang da, W., Sherman, B. T., and Lempicki, R. A. (2009b). Systematic and integrative analysis of large gene lists using DAVID bioinformatics resources. Nat. Protoc. 4, 44-57. doi: 10.1038/nprot.2008.211

Jang, H., Choi, D. E., Kim, H., Cho, E. J., and Youn, H. D. (2007). Cabin1 represses MEF2 transcriptional activity by association with a methyltransferase, SUV39H1. J. Biol. Chem. 282, 11172-11179. doi: 10.1074/jbc.M611199200

Joosten, A., Matzinger, O., Jeanneret-Sozzi, W., Bochud, F., and Moeckli, R. (2013). Evaluation of organ-specific peripheral doses after 2-dimensional, 3dimensional and hybrid intensity modulated radiation therapy for breast cancer based on Monte Carlo and convolution/superposition algorithms: implications for secondary cancer risk assessment. Radiother. Oncol. 106, 33-41. doi: 10.1016/j.radonc.2012.11.012

Kaneko, Y. S., Watanabe, N., Morisaki, H., Akita, H., Fujimoto, A., Tominaga, K., et al. (1999). Cell-cycle-dependent and ATM-independent expression of human Chk1 kinase. Oncogene 18, 3673-3681. doi: 10.1038/sj.onc.1202706 
Kaup, S., Grandjean, V., Mukherjee, R., Kapoor, A., Keyes, E., Seymour, C. B., et al. (2006). Radiation-induced genomic instability is associated with DNA methylation changes in cultured human keratinocytes. Mutat. Res. 597, 87-97. doi: 10.1016/j.mrfmmm.2005.06.032

Keogh, M. C., Kim, J. A., Downey, M., Fillingham, J., Chowdhury, D., Harrison, J. C., et al. (2006). A phosphatase complex that dephosphorylates gammaH2AX regulates DNA damage checkpoint recovery. Nature 439, 497-501. doi: 10.1038 /nature 04384

Kleinerman, R. A. (2006). Cancer risks following diagnostic and therapeutic radiation exposure in children. Pediatr. Radiol. 36(Suppl. 2), 121-125. doi: 10.1007/s00247-006-0191-5

Kovalchuk, O., Burke, P., Besplug, J., Slovack, M., Filkowski, J., and Pogribny, I. (2004). Methylation changes in muscle and liver tissues of male and female mice exposed to acute and chronic low-dose X-ray-irradiation. Mutat. Res. 548, 75-84. doi: 10.1016/j.mrfmmm.2003.12.016

Krasin, M. J., Constine, L. S., Friedman, D. L., and Marks, L. B. (2010). Radiationrelated treatment effects across the age spectrum: differences and similarities or what the old and young can learn from each other. Semin. Radiat. Oncol. 20, 21-29. doi: 10.1016/j.semradonc.2009.09.001

Krishnamurthy, J., Ramsey, M. R., Ligon, K. L., Torrice, C., Koh, A., BonnerWeir, S., et al. (2006). pl6INK4a induces an age-dependent decline in islet regenerative potential. Nature 443, 453-457. doi: 10.1038/nature05092

Lachner, M., O'carroll, D., Rea, S., Mechtler, K., and Jenuwein, T. (2001). Methylation of histone $\mathrm{H} 3$ lysine 9 creates a binding site for HP1 proteins. Nature 410, 116-120. doi: 10.1038/35065132

Lahtz, C., Bates, S. E., Jiang, Y., Li, A. X., Wu, X., Hahn, M. A., et al. (2012). Gamma irradiation does not induce detectable changes in DNA methylation directly following exposure of human cells. PLOS ONE 7:e44858. doi: 10.1371/journal.pone.0044858

Latella, L., Lukas, J., Simone, C., Puri, P. L., and Bartek, J. (2004). Differentiationinduced radioresistance in muscle cells. Mol. Cell. Biol. 24, 6350-6361. doi: 10.1128/MCB.24.14.6350-6361.2004

Lehnertz, B., Ueda, Y., Derijck, A. A., Braunschweig, U., Perez-Burgos, L., Kubicek, S., et al. (2003). Suv39h-mediated histone H3 lysine 9 methylation directs DNA methylation to major satellite repeats at pericentric heterochromatin. Curr. Biol. 13, 1192-1200. doi: 10.1016/S0960-9822(03)00432-9

Lowe, S. W., Schmitt, E. M., Smith, S. W., Osborne, B. A., and Jacks, T. (1993). p53 is required for radiation-induced apoptosis in mouse thymocytes. Nature 362, 847-849. doi: 10.1038/362847a0

Luo, J., Li, M., Tang, Y., Laszkowska, M., Roeder, R. G., and Gu, W. (2004). Acetylation of p53 augments its site-specific DNA binding both in vitro and in vivo. Proc. Natl. Acad. Sci. U.S.A. 101, 2259-2264. doi: 10.1073/pnas.0308762101

Melcher, M., Schmid, M., Aagaard, L., Selenko, P., Laible, G., and Jenuwein, T. (2000). Structure-function analysis of SUV39H1 reveals a dominant role in heterochromatin organization, chromosome segregation, and mitotic progression. Mol. Cell. Biol. 20, 3728-3741. doi: 10.1128/MCB.20.10.3728-3741.2000

Messeguer, X., Escudero, R., Farre, D., Nunez, O., Martinez, J., and Alba, M. M. (2002). PROMO: detection of known transcription regulatory elements using species-tailored searches. Bioinformatics 18, 333-334. doi: 10.1093/bioinformatics/18.2.333

Mungamuri, S. K., Benson, E. K., Wang, S., Gu, W., Lee, S. W., and Aaronson, S. A. (2012). p53-mediated heterochromatin reorganization regulates its cell fate decisions. Nat. Struct. Mol. Biol. 19, 478-484, S471. doi: 10.1038/nsmb.2271

Narita, M., Nunez, S., Heard, E., Lin, A. W., Hearn, S. A., Spector, D. L., et al. (2003). $\mathrm{Rb}$-mediated heterochromatin formation and silencing of E2F target genes during cellular senescence. Cell 113, 703-716. doi: 10.1016/S0092-8674(03)00401-X

Neal, J. V., and Potten, C. S. (1981). Effect of low dose ionizing radiation on the murine pericryptal fibroblast sheath: radiation damage in a mesenchymal system in vivo. Int. J. Radiat. Biol. Relat. Stud. Phys. Chem. Med. 39, 175-183. doi: 10.1080/09553008114550191

Nelson, J. D., Denisenko, O., and Bomsztyk, K. (2006). Protocol for the fast chromatin immunoprecipitation (ChIP) method. Nat. Protoc. 1, 179-185. doi: 10.1038/nprot.2006.27

Nielsen, S. J., Schneider, R., Bauer, U. M., Bannister, A. J., Morrison, A., O'carroll, D., et al. (2001). Rb targets histone H3 methylation and HP1 to promoters. Nature 412, 561-565. doi: 10.1038/35087620

Noda, A., Hirai, Y., Hamasaki, K., Mitani, H., Nakamura, N., and Kodama, Y. (2012). Unrepairable DNA double-strand breaks that are generated by ionising radiation determine the fate of normal human cells. J. Cell Sci. 125, 5280-5287. doi: $10.1242 /$ jcs. 101006

O'sullivan, R. J., Kubicek, S., Schreiber, S. L., and Karlseder, J. (2010). Reduced histone biosynthesis and chromatin changes arising from a damage signal at telomeres. Nat. Struct. Mol. Biol. 17, 1218-1225. doi: 10.1038/nsmb.1897

Park, J. A., Kim, A. J., Kang, Y., Jung, Y. J., Kim, H. K., and Kim, K. C. (2011). Deacetylation and methylation at histone $\mathrm{H} 3$ lysine 9 (H3K9) coordinate chromosome condensation during cell cycle progression. Mol. Cells 31, 343-349. doi: 10.1007/s10059-011-0044-4

Peters, A. H., O'carroll, D., Scherthan, H., Mechtler, K., Sauer, S., Schofer, C., et al. (2001). Loss of the Suv39h histone methyltransferases impairs mammalian heterochromatin and genome stability. Cell 107, 323-337. doi: 10.1016/S00928674(01)00542-6

Poehlmann, A., Habold, C., Walluscheck, D., Reissig, K., Bajbouj, K., Ullrich, O., et al. (2011). Cutting edge: Chk1 directs senescence and mitotic catastrophe in recovery from $\mathrm{G}(2)$ checkpoint arrest. J. Cell. Mol. Med. 15, 1528-1541. doi: 10.1111/j.1582-4934.2010.01143.x

Rea, S., Eisenhaber, F., O'carroll, D., Strahl, B. D., Sun, Z. W., Schmid, M., et al. (2000). Regulation of chromatin structure by site-specific histone H3 methyltransferases. Nature 406, 593-599. doi: 10.1038/35020506

Rodier, F., Coppe, J. P., Patil, C. K., Hoeijmakers, W. A., Munoz, D. P., Raza, S. R., et al. (2009). Persistent DNA damage signalling triggers senescenceassociated inflammatory cytokine secretion. Nat. Cell Biol. 11, 973-979. doi: $10.1038 /$ ncb1909

Safran, M., Dalah, I., Alexander, J., Rosen, N., Iny Stein, T., Shmoish, M., et al. (2010). GeneCards Version 3: the human gene integrator. Database (Oxford) 2010:baq020. doi: 10.1093/database/baq020

Scaffidi, P., and Misteli, T. (2006). Lamin A-dependent nuclear defects in human aging. Science 312, 1059-1063. doi: 10.1126/science.1127168

Schellenberg, A., Lin, Q., Schuler, H., Koch, C. M., Joussen, S., Denecke, B., et al. (2011). Replicative senescence of mesenchymal stem cells causes DNAmethylation changes which correlate with repressive histone marks. Aging (Albany N.Y.) 3, 873-888.

Seluanov, A., Mittelman, D., Pereira-Smith, O. M., Wilson, J. H., and Gorbunova, V. (2004). DNA end joining becomes less efficient and more error-prone during cellular senescence. Proc. Natl. Acad. Sci. U.S.A. 101, 7624-7629. doi: 10.1073/pnas.0400726101

Sidler, C., Woycicki, R., Ilnytskyy, Y., Metz, G., Kovalchuk, I., and Kovalchuk, O. (2013). Immunosenescence is associated with altered gene expression and epigenetic regulation in primary and secondary immune organs. Front. Genet. 4:211. doi: 10.3389/fgene.2013.00211

Sidler, C., Woycicki, R., Li, D., Wang, B., Kovalchuk, I., and Kovalchuk, O. (2014). A role for SUV39H1-mediated $\mathrm{H} 3 \mathrm{~K} 9$ trimethylation in the control of genome stability and senescence in WI38 human diploid lung fibroblasts. Aging (Albany N.Y.) 6, 545-563.

Terasima, T., and Tolmach, L. J. (1963). Variations in several responses of HeLa cells to $\mathrm{x}$-irradiation during the division cycle. Biophys. J. 3, 11-33. doi: 10.1016/S0006-3495(63)86801-0

Tsunoda, T., and Takagi, T. (1999). Estimating transcription factor bindability on DNA. Bioinformatics 15, 622-630. doi: 10.1093/bioinformatics/15.7.622

Vandesompele, J., De Preter, K., Pattyn, F., Poppe, B., Van Roy, N., De Paepe, A., et al. (2002). Accurate normalization of real-time quantitative RT-PCR data by geometric averaging of multiple internal control genes. Genome Biol. 3:RESEARCH0034. doi: 10.1186/gb-2002-3-7-research0034

Wakabayashi, Y., Tamiya, T., Takada, I., Fukaya, T., Sugiyama, Y., Inoue, N., et al. (2011). Histone 3 lysine 9 (H3K9) methyltransferase recruitment to the interleukin-2 (IL-2) promoter is a mechanism of suppression of IL-2 transcription by the transforming growth factor-beta-Smad pathway. J. Biol. Chem. 286 , 35456-35465. doi: 10.1074/jbc.M111.236794

Warters, R. L. (1992). Radiation-induced apoptosis in a murine T-cell hybridoma. Cancer Res. 52, 883-890.

Wolf, F. I., Torsello, A., Covacci, V., Fasanella, S., Montanari, M., Boninsegna, A., et al. (2002). Oxidative DNA damage as a marker of aging in WI-38 human fibroblasts. Exp. Gerontol. 37, 647-656. doi: 10.1016/S0531-5565(02)00005-0

Xu, B., Kim, S. T., Lim, D. S., and Kastan, M. B. (2002). Two molecularly distinct $\mathrm{G}(2) / \mathrm{M}$ checkpoints are induced by ionizing irradiation. Mol. Cell. Biol. 22, 1049-1059. doi: 10.1128/MCB.22.4.1049-1059.2002

Yamaoka, M., Kusunoki, Y., Kasagi, F., Hayashi, T., Nakachi, K., and Kyoizumi, S. (2004). Decreases in percentages of naive CD4 and CD8 T cells and increases 
in percentages of memory CD8 T-cell subsets in the peripheral blood lymphocyte populations of A-bomb survivors. Radiat. Res. 161, 290-298. doi: 10.1667/RR3143

Ye, C., Zhang, X., Wan, J., Chang, L., Hu, W., Bing, Z., et al. (2013). Radiationinduced cellular senescence results from a slippage of long-term $G 2$ arrested cells into G 1 phase. Cell Cycle 12, 1424-1432. doi: 10.4161/cc.24528

Zheng, H., Chen, L., Pledger, W. J., Fang, J., and Chen, J. (2014). p53 promotes repair of heterochromatin DNA by regulating JMJD2b and SUV39H1 expression. Oncogene 33, 734-744. doi: 10.1038/onc. 2013.6

Conflict of Interest Statement: The authors declare that the research was conducted in the absence of any commercial or financial relationships that could be construed as a potential conflict of interest.
Received: 02 August 2014; paper pending published: 12 October 2014; accepted: 05 November 2014; published online: 21 November 2014.

Citation: Sidler C, Li D, Wang B, Kovalchuk I and Kovalchuk O (2014) SUV39H1 downregulation induces deheterochromatinization of satellite regions and senescence after exposure to ionizing radiation. Front. Genet. 5:411. doi: 10.3389/fgene. 2014.00411

This article was submitted to Genetics of Aging, a section of the journal Frontiers in Genetics.

Copyright (c) 2014 Sidler, Li, Wang, Kovalchuk and Kovalchuk. This is an openaccess article distributed under the terms of the Creative Commons Attribution License (CC BY). The use, distribution or reproduction in other forums is permitted, provided the original author(s) or licensor are credited and that the original publication in this journal is cited, in accordance with accepted academic practice. No use, distribution or reproduction is permitted which does not comply with these terms. 